\title{
A EDUCAÇÃO PROGRESSIVA COMO ALTERNATIVA: AS VOZES DOS EDUCADORES
}

\author{
MARIA LUÍSA BRANCO*
}

RESUMO: A partir de um estudo conduzido mediante a realização de entrevistas semiestruturadas a seis educadoras que trabalham ou trabalharam em escolas progressivas na cidade de Nova Iorque, exploraremos neste texto algumas das propostas que fazem da educação progressiva uma alternativa credível para a implementação de uma educação democrática, em oposição ao atual quadro neoliberal vigente nos Estados Unidos da América. Com base no tratamento das entrevistas feita com recurso a uma análise temática, é possível concluir que a educação progressiva se baseia na organização de uma aprendizagem integral que tem em conta a realidade dos alunos e que fortalece a partilha de conhecimentos e responsabilidades, favorecendo a aquisição de uma visão crítica e da capacidade de intervir no meio envolvente.

Palavras-chave: Educação progressiva. Educação democrática. Justiça social. Prestação de contas.

\section{Progressive education as an alternative: THE EDUCATORS' VOICES}

ABSTRACT: In this paper, we will explore the main proposals of progressive education nowadays that make it a credible alternative for the implementation of a democratic education, as opposed to the neo-liberal framework established in the United States of America. With this purpose, we have interviewed six educators in New York City that work or had worked in progressive schools. From a thematic analysis of the interviews, we can conclude that progressive education is based upon the organization of an integral learning that establishes a connection with the students' world, enhancing the ability to share knowledge and responsibilities as well as promoting the acquisition of a critical perspective and the ability to intervene in the world.

Key words: Progressive education. Democratic education. Social justice. Accountability.

* $\quad$ Departamento de Psicologia e Educação da Universidade da Beira Interior. Covilhã - Portugal. Contato com a autora: <lbranco@ubi.pt> 


\title{
L'ENSEIGNEMENT PROGRESSIF COMME ALTERNATIVE: \\ LES VOIX DES EDUCATEURS
}

\begin{abstract}
RÉSUMÉ: D'après une étude menée par la réalisation d'entrevues semi-structurées à six enseignantes qui travaillent ou qui ont travaillé dans des écoles progressives à New York, cet article explore quelques propositions de l'enseignement progressif qui constituent une alternative crédible pour la mise en œuvre d'un enseignement démocratique, par opposition au cadre néolibéral en vigueur dans les États Unis d'Amérique. Basé sur la saisie des résultats d'entrevues, menée à l'aide d'une analyse thématique, nous concluons que l'enseignement progressif est fondé sur l'organisation d'un apprentissage intégral qui prend en compte la réalité des apprenants et améliore le partage de connaissances et de responsabilités, tout comme l'acquisition d'un regard critique et la capacité d'intervention dans la réalité.
\end{abstract}

Mots-clés: Éducation progressive. Éducation démocratique. Justice sociale. Accountability.

\section{Introdução}

A

educação progressiva teve início nos finais do século XIX nos Estados Unidos da América (ao mesmo tempo em que, na Europa, começava o vasto movimento de renovação pedagógica que ficou conhecido por Educação Nova), constituindo, hoje, neste país, uma longa e consolidada tradição educacional (SEMEL, 2008). A extraordinária longevidade e diversidade da educação progressiva torna, contudo, a sua definição difícil. Apesar de se basear numa filosofia específica da educação, onde o pensamento de John Dewey desempenha um papel crucial, é entendida por muitos como uma série de práticas de ensinoaprendizagem opostas às tradicionais, demarcando-se de um ensino baseado na transmissão de conteúdos e centrado no professor. De acordo com Norris (2004), a educação progressiva pode ser vista hoje como um movimento multifacetado, com vários componentes comuns, nomeadamente: o papel fundacional ocupado pelo pensamento de Dewey; uma oposição à educação tradicional em termos de métodos, matérias de estudo e propósitos; uma educação centrada na criança e no seu desenvolvimento total; uma abordagem baseada na resolução de problemas, tendo em vista a criação e a melhoria de competências de vida; uma focagem na prática; a integração do conhecimento através de situações reais; a visão da escola como uma sociedade embriônica e um instrumento primário de mudança social; uma concepção democrática de educação.

Vários autores (CARINI, 2000; NORRIS, 2004; MEIER, 2002b; SKAKER; HEILMAN, 2008; ZIMILES, 2008) realçam a educação centrada na criança como o aspecto mais relevante da educação progressiva. Por detrás deste aspecto está o pensamento de Dewey, segundo o qual a criança deve ser o centro da educação, querendo com 
isto dizer que o currículo deve ser planeado tendo em conta a realidade da criança, constituindo esta a base para efetuar a seleção dos conteúdos e das estratégias de aprendizagem (DEWEY, 1902). Como refere Norris (2004, p. 42, tradução nossa), “Dewey acreditava que qualquer coisa que fosse ensinada à criança de forma sistemática deveria começar com a curiosidade natural da criança, renunciando assim à tradicional fragmentação do currículo e sua transmissão". A importância de corresponder às necessidades da criança está estreitamente relacionada com a concepção da criança como um indivíduo complexo, com várias dimensões. Cada criança tem as suas próprias necessidades, forças e fraquezas, devendo a educação ser cuidadosamente planeada no sentido de corresponder a esses aspectos. Recentemente, o desenvolvimento da Revisão Descritiva da Criança, ${ }^{1}$ uma metodologia relacionada com os ideais progressivos, cujo objetivo consiste em apreender a pessoa "na sua unicidade e complexidade" (CARINI, 2000, p. 4, tradução nossa), enfatiza esta característica da educação progressiva.

O que está por detrás da importância concedida às necessidades e interesses da criança é o papel atribuído à experiência, encarada como a base do conhecimento e da aprendizagem no pensamento de Dewey (ROSKELLY, 2009). Na concepção deste autor, a "educação deve ser conduzida de forma inteligente com base na experiência" (DEWEY, 1997b, p. 33, tradução nossa) e no sentido de alargar a mesma. Significa isto que uma experiência, para ser educativa e não acidental, deve ser dotada de um propósito, tendo simultaneamente em conta os poderes e os objetivos daqueles que são ensinados, no sentido de alterar as suas condições objetivas e subjetivas. Por conseguinte, estabelecendo a equivalência entre vida e educação, Dewey coloca o crescimento como o objetivo e o veículo da própria vida. Segundo ele, "uma experiência verdadeiramente educativa é aquela que conduz a mais educação e crescimento" (apud SHAKER; HEILMAN, 2008, p. 176, tradução nossa), proporcionando a reconstrução da experiência prévia e possibilitando que o indivíduo lide efetivamente com situações posteriores. A integração de sucessivas experiências, mediante uma organização ativa dos factos e das ideias, constitui a chave para o desenvolvimento de uma personalidade completa e integrada.

O papel central da experiência na aprendizagem fornece também a base para uma concepção democrática de educação. Como refere Roskelly (2009, p. 108, tradução nossa), "a democracia insiste que as respostas para os problemas não provêm de fora de nós mesmos, mas daquilo que temos à mão, daquilo que sabemos e vivemos". De acordo com Dewey (1997b), os arranjos democráticos proporcionam uma experiência superior suportada pelo exercício das liberdades individuais e por relações humanas baseadas na decência. Numa escola democrática, as crianças devem aprender a viver umas com as outras, prosseguindo objetivos comuns (MEIER, 2002b). Esta é outra importante característica da educação progressiva que tem sido enfatizada. Defendendo uma abordagem educativa centrada na criança e que tem como objetivo 
a sua personalização, a educação progressiva possui igualmente uma vertente comunitária, salientando a importância da cooperação e do respeito e a promoção da diversidade e do compromisso (MEIER, 2002a).

Segundo Shaker e Heilman (2008), os adeptos da educação progressiva estão seriamente comprometidos com uma visão democrática da sociedade, cuja concretização passa pelo assegurar de oportunidades iguais para todos. Reconhecendo a importância de garantir o bem estar material, realçam, contudo, a necessidade de fazê-lo num contexto de sustentabilidade, entendido em sentido social e ambiental. Em termos do senso comum, porém, a educação progressiva é encarada, frequentemente, como uma perspectiva romântica, responsável pelo aumento da indisciplina e pelo abaixamento dos padrões de qualidade do ensino-aprendizagem, caracterizando-se, ainda, por um irrealismo econômico. Esta visão, que tem sido alimentada por vários autores e que procuraremos refutar ao longo deste texto, considera a relação preconizada entre democracia e educação como um ataque à autoridade adulta e como uma via aberta para a permissividade nas escolas (NORRIS, 2004). De acordo com Zimiles (2008), as condições que asseguraram, de forma quase ininterrupta, o sucesso das escolas progressivas desde os inícios até aos anos de 1950, não se aplicam mais às escolas de hoje. A reforma progressiva funcionou bem em pequenas escolas privadas e com crianças de famílias comprometidas com este tipo de educação. Norris (op. cit.) corrobora esta opinião, ao defender que a educação progressiva constitui preferencialmente a escolha das famílias de classe média, sendo rejeitada pelas famílias de baixos rendimentos. Neste contexto, Zimiles (op. cit.) salienta ainda as enormes mudanças sofridas pela infância, considerando que as crianças que frequentam hoje as escolas públicas partilham um quadro psicológico muito diferente, carecendo de estrutura e autoridade nas suas vidas. Esta constatação leva-o a concluir que, embora sendo uma abordagem educativa com vários aspectos positivos, "é menos capaz do que era no passado para satisfazer as necessidades das crianças" (ZIMILES, 2008, p. 169, tradução nossa).

A generalização da perspectiva neoliberal, marcada pela dominância de objetivos econômicos e pela implementação de medidas de prestação de contas (SHAKER; HEILMAN, 2008), definitivamente estabelecida com a promulgação da legislação No Child Left Behind (NCLB), em 2002,2 secundarizou a visão da missão humanística das escolas, colocando em risco o objetivo de integrar e promover a democracia através da escolarização. A dominância dos testes estandardizados ${ }^{3}$ em educação conduziu a um empobrecimento do currículo e das práticas de ensino-aprendizagem, muito orientadas para a obtenção de sucesso nesses testes, na medida em que os resultados destes condicionam não só o percurso escolar dos alunos, mas também a própria viabilidade das escolas e a manutenção do lugar dos diretores e dos professores. Em consequência da aplicação do NCLB, as políticas educacionais de hoje, nos EUA, 
estão marcadas por um retorno aos métodos tradicionais e ao ensino das matérias básicas (Inglês e Matemática).

A lógica de prestação de contas é animada pela ideia de que, "forçando a escola a publicar os seus resultados de modo a serem conhecidos pelo público em geral, ninguém pode esconder-se por detrás do emaranhado burocrático e o público é informado de forma justa acerca do modo como os dólares estão a ser usados" (NORRIS, 2004, p. 129, tradução nossa). Os defensores destas práticas consideram que, "sem nada para esconder, as escolas e os líderes escolares serão forçados a produzir, melhorar ou fechar" (idem, ibid.). Para Roskelly (2009), estas perspectivas revelam a dominância do taylorismo em educação, tendo como primeiro objetivo o sistema e o seu controlo e não as pessoas e o desenvolvimento das suas capacidades. Entre os efeitos perversos do NCLB, Kohn (2004) salienta, ainda, a desprofissionalização dos professores e o empobrecimento da ideia de educação.

Os adeptos da educação progressiva têm-se pronunciado favoravelmente acerca da avaliação e da prestação de contas, rejeitando, contudo, um conceito estreito de avaliação baseado numa única medida e defendendo formas alternativas e mais substanciais de avaliação como, por exemplo, os portefólios (MEIER, 2002a; SHAKER; HEILMAN, 2008; KRECHEVSKY; RIVARD; BURTON, 2010). Consideram que a aplicação do NCLB é enformada por uma lógica punitiva, conduzindo a insistência nos testes a uma classificação ao invés de uma avaliação real dos alunos e do trabalho realizado nas escolas. A ênfase nos testes põe ainda em causa a capacidade dos professores e dos pais de avaliar a aprendizagem das suas crianças, colocando-os à margem deste processo (MEIER, 2002a; NEILL, 2004; PURPEL, 2009). Consequentemente, os educadores progressivos discordam do que consideram ser a aplicação das leis do mercado às escolas, acreditando que o propósito da educação reside não só na preparação para um mercado de trabalho competitivo, mas também na preservação e aprofundamento da democracia (NODDINGS, 2005; GODMAN, 2006).

Tendo em conta que há cada vez mais pessoas cientes dos efeitos perniciosos da aplicação das medidas emanadas do NCLB, o objetivo deste artigo consiste em explorar as propostas da educação progressiva na atualidade, que fazem dela uma alternativa credível à prossecução de uma genuína educação democrática, nas vozes dos seus seguidores.

\section{Sujeitos e contexto do estudo}

Neste estudo, entrevistámos seis educadoras da cidade de Nova Iorque que foram identificadas como sujeitos-chave. Os nomes destas educadoras foram indicados por personalidades ligadas à formação de professores e à educação progressiva, pelo seu compromisso com os ideais progressivos. Com idades compreendidas ente os 80 e 
os 40 anos, têm em comum o facto de desempenharem ou terem desempenhado lugares de direção em escolas progressivas (três foram diretoras de escolas públicas dessa natureza na cidade de Nova Iorque, encontrando-se de momento reformadas, mas mantendo uma ligação ao mundo da educação; outras duas são diretoras de escolas públicas progressivas e uma terceira desempenha funções de responsabilidade numa escola privada, também na cidade de Nova Iorque). $O$ facto de se ter escolhido profissionais a trabalhar na cidade de Nova Iorque tem uma razão de ser. Como referido por Ravitch (2010), esta cidade funciona como uma espécie de teste nacional para as reformas educativas inspiradas no modelo de mercado, que estão, na prática, a "deixar muitas crianças para trás". O compromisso com a educação progressiva assume neste contexto um significado particular de resistência, implicando criatividade e reflexão.

\section{Método}

Os dados foram recolhidos mediante a aplicação de entrevistas semiestruturadas. Foi seguido um guião construído em torno de três itens: relação pessoal com a educação progressiva; apreciação da educação progressiva; a educação progressiva na atualidade. As entrevistas foram aplicadas entre abril e maio de 2011, todas de forma presencial e duraram entre quarenta minutos e uma hora e meia. Foram salvaguardadas as devidas precauções éticas de anonimato dos sujeitos. As entrevistas foram todas gravadas e transcritas na íntegra.

Os dados foram tratados com recurso a uma análise temática. O objetivo deste tipo de análise consiste em identificar temas que concorram para a descrição do fenômeno que está a ser estudado (FEREDAY; MUIR-CROCHRANE, 2006). Implica uma imersão nos dados com o objetivo de se identificarem padrões. Estes padrões são agrupados em subtemas e, a partir da reunião destes, verifica-se a emergência de um conjunto de temas (ARONSON, 1994).

A fiabilidade dos dados e da sua interpretação foi acautelada mediante a devolução da transcrição das entrevistas e dos temas encontrados às entrevistadas para que se pronunciassem. As transcrições da análise dos resultados foram, ainda, objeto de uma revisão por pares (GUBA; LINCOLN, 1988). Exploraremos, de seguida, alguns dos temas que se relacionam diretamente com os objetivos deste artigo.

\section{Resultados}

\section{Aprender em contexto progressivo}

As entrevistadas são unânimes na identificação da educação progressiva como baseada numa forma diferente de aprendizagem. Isto significa uma educação 
que não é meramente transmissiva, mas na qual os estudantes são confrontados com oportunidades e desafios capazes de potenciar a sua aprendizagem e o seu desenvolvimento. Nas palavras de uma das educadoras: "Penso que a educação progressiva é... no seu melhor... uma educação orientada para o aluno, no sentido do professor ou da escola... proporcionarem oportunidades... aos alunos para aprender... de várias formas e... depressa, devagar, conforme necessário" (E1).

A criação destas oportunidades e desafios exige que se tenha em conta a especificidade dos estudantes e a sua realidade atual. Como refere uma das educadoras, implica conceber "um currículo mais vivo e apelativo" (E6). Por conseguinte, aprender em contexto progressivo significa também aprender de forma ativa, colocando os estudantes a experimentar coisas e a refletir sobre elas com o objetivo de estabelecer relações e dar sentido à sua própria experiência.

Uma aprendizagem integral está associada, segundo algumas das entrevistadas, à ideia da aprendizagem em contexto progressivo. Nas palavras de uma das educadoras, aprender em contexto progressivo envolve "um humanismo no sentido de uma educação integrada, algo que tem a ver com a pessoa na sua totalidade" (E2), exigindo diversas formas de aprendizagem (académica, social, cívica e moral), assim como uma organização mais flexível e diversa da escola e da sala de aula. Algumas entrevistadas referem-se ainda à aprendizagem em contexto progressivo como um processo de corresponsibilização, através de uma aprendizagem em conjunto que propicia o acesso a outras perspectivas e o progredir, tendo em conta a combinação dessas perspectivas diferentes, no fundo um caminho para uma cidadania democrática.

\section{Um local onde as pessoas são importantes}

As escolas progressivas foram descritas como locais onde as pessoas são importantes. De acordo com uma das educadoras, uma escola progressiva "tem de ser um local onde se verifiquem relações de suporte e de encorajamento" (E1), onde os professores tenham fé na capacidade de aprender das crianças e tentem potenciar esta capacidade por todos os meios ao seu alcance. Ou seja, um local onde as crianças sejam estimuladas, mediante a criação de oportunidades, a experimentar coisas, se iniciem nas artes e usufruam de um ambiente esteticamente atrativo.

Várias educadoras corroboraram a ideia das escolas progressivas como locais onde as pessoas são importantes, ao referirem que, apesar de proporcionarem estrutura e orientação, se caracterizam por serem locais não punitivos, marcados pela flexibilidade e pela ênfase dada ao pensamento crítico, assim como à promoção da capacidade de escolha. Como mencionado por outra educadora, para que uma escola seja considerada progressiva é crucial "a ideia de que a estrutura, a política e a teoria estão abertas a questões e podem despoletar novas questões" (E2). 
A maior parte das educadoras referiu-se, ainda, à importância de promover a participação dos estudantes, no sentido de dar visibilidade e de validar as suas vozes. Como sustentado por uma delas: "Considero que uma das coisas que faz de uma escola uma escola progressiva é... a valorização da voz dos estudantes, e isso pode ser feito de forma oficial, através das associações de estudantes, ou de forma não oficial, através do modo como falamos com eles e os escutamos no dia a dia" (E4).

O impacto desta participação deve começar na sala de aula, como referido por outra educadora: "As ideias dos meus estudantes são importantes porque acho que devem ser valorizadas, mas... são importantes também porque determinam o que se passa na sala de aula" (E3).

\section{Ensinar é partilhar um caminho}

Outro tema que emerge das entrevistas é a concepção do ensinar como um processo dinâmico, o percorrer um caminho de forma partilhada. Ensinar em contexto progressivo é, assim, percebido por várias entrevistadas como um processo exigente. Nas palavras de uma delas: "Hoje em dia, a minha ideia do que é ser um educador progressivo consiste em estar à altura, e isso significa não só fazer as coisas como os outros fazem ou como fizeram comigo, mas estar na crista da onda, estar na avant-garde e tentar coisas novas, mediante uma cuidadosa planificação" (E6).

Ensinar nesta perspectiva exige, pois, otimismo e confiança, assim como a capacidade de correr riscos, incluindo a partilha de conhecimentos e de responsabilidades, conduzindo a um desenvolvimento profissional a nível pessoal e coletivo, como uma educadora recorda: "Bem, eu era professora de Inglês e tornei-me professora de Humanidades, pelo que tive de estudar História, mas o professor de História com quem eu estava a trabalhar também teve de estudar Inglês, foi um esforço colaborativo para delinear o currículo e as estratégias a utilizar" (E5).

Tendo em conta que todos os estudantes têm direito a aprender e a ser bemsucedidos, o ensino é ainda perspectivado de uma forma particularmente responsável. Os professores devem estar cientes das razões pelas quais os estudantes não conseguem aprender, consciencializando-se das dificuldades que experimentam no sentido de descobrir formas para ajudá-los a superar as mesmas. Isto implica a adoção de um estilo diferente, como salientado pela educadora previamente citada:

Parte da transição para a educação progressiva, para uma forma diferente de chegar às crianças, foi colocar-me um pouco na retaguarda, dividir o controlo, partilhar as inquietações, não ter de ser especialista em tudo, quando não me sentia segura de alguma coisa, ser capaz de dizer: embora procurar! (E5) 


\section{Adquirir uma voz e fazer a diferença}

A possibilidade de crescimento de acordo consigo mesmo associada à capacidade de intervir no meio envolvente são identificadas como os principais efeitos da educação progressiva. Nas palavras de uma das entrevistadas: "Considero que o resultado mais importante da educação progressiva é ver jovens que terminam o ensino secundário dotados de uma profundidade de análise e de uma paixão pelo mundo, e que sabem muito provavelmente o que querem fazer com a sua vida" (E4). A educação progressiva é identificada como uma educação diferenciada, que não impõe o mesmo padrão a todos, mas que permite à criança/estudante desenvolverse e expressar-se de acordo com a sua singularidade. Nas palavras de outra entrevistada, referindo-se aos benefícios dessa educação:

A vantagem em teoria, e a maior parte das vezes também na prática [da educação progressiva], é não ser muito limitativa, de modo que o estudante pode experimentar e errar e encontrar, ou ser ajudado a encontrar, formas de superar as suas dificuldades, mas sempre desenvolvendo-se no sentido daquilo que é, em vez de encaixar num padrão pré-definido pela escola ou pelo professor. (E3, p. 4)

Adquirir uma voz implica um autoenvolvimento na aprendizagem e favorece o desenvolvimento de um sentido de autoconfiança e de orgulho. Como referido por uma das educadoras: "O que estamos a fazer com os estudantes que nos chegam, e que lutam com dificuldades académicas e/ou emocionais, é ajudá-los a envolveremse mais poderosa e autenticamente na sua aprendizagem e a desenvolverem, deste modo, orgulho no seu trabalho" (E4).

Esta parece constituir a chave para a formação de pessoas resilientes e com capacidade de aprender ao longo da vida, pessoas capazes de lutar e de correr riscos, mas que também se preocupam com os outros, que pautam o seu comportamento por princípios éticos e de justiça social, acostumadas a escutar outros pontos de vista e a partilhar, apostadas em fazer a diferença.

\section{Uma abordagem educativa exigente}

As educadoras entrevistadas descrevem a educação progressiva como uma abordagem exigente. Como referido por uma delas: "Sem dúvida, exige muita orientação, leva mais tempo, é mais individualizada" (E5). Para o professor, pode mesmo chegar a ser absorvente, como referido pela mesma educadora: "o problema das pessoas que optam por outras formas de educar é que isto exige muito envolvimento com as escolas, roubando tempo a outras partes da vida" (E5).

Para além de ser uma abordagem educativa morosa, implica também uma adaptação que pode ser complicada para os estudantes que estão habituados a outro 
tipo de educação. Como menciona uma das educadoras, refletindo sobre a experiência da sua própria escola:

Penso que, por vezes, quando os estudantes completaram o ensino básico num outro tipo de escola, a transição pode ser difícil, especialmente para os estudantes habituados a um local autoritário, onde os professores possivelmente gritavam para serem obedecidos ou mesmo os pais, ao passo que nós raciocinamos com eles. (E4)

Apesar de a educação progressiva constituir uma proposta exequível, o espírito do tempo não lhe é favorável, como realça outra educadora:

Se acharmos que há outra maneira de fazer as coisas e tivermos fé nisso, nada nos vai impedir de ir para frente e organizar a escola dessa forma. Sem dúvida que é possível! Acho que o que está a impedir as pessoas é esta história da substituição dos diretores e dos professores, o que nos deixa numa espécie de ciclo onde... este sistema defende um conjunto diferente de ideias! (E6)

\section{Um olhar crítico sobre as atuais políticas educacionais}

A maioria das educadoras entrevistadas considera que as políticas educacionais que estão a ser implementadas nos Estados Unidos da América são responsáveis pela criação e aprofundamento de desigualdades. Nas palavras de uma delas,

Penso que o facto de um estudante de uma família desfavorecida não conseguir ler ou expressar por escrito as suas ideias, e ser apenas capaz de repetir uma resposta ou usar um único tipo de parágrafo... esta desvantagem vai-se manter à medida que a vida desta criança avançar, e ela entrar no mercado de trabalho. É uma desvantagem que arrasta consigo, quer se candidate à universidade ou a um emprego. (E 3)

O facto é que muitas crianças estão a "ser deixadas para trás", como acentuado por uma das educadoras:

Bem... o que eu acho é que hoje na América, neste país, as coisas estão definitivamente a mudar, a tomar um rumo mais tradicional e infelizmente isto significa voltar a colocar crianças na rua, com as escolas a rejeitá-las porque não se saem bem nos testes estandardizados, ou porque não aparecem na escola diariamente, ou porque andam ocupadas com outros assuntos. (E5)

Paradoxalmente, o sistema atual parece conter algumas sementes de mudança, nomeadamente a ideia das metas comuns de aprendizagem, que podem ser aperfeiçoadas no sentido de se tornarem mais flexíveis, e a ideia da escolha. $O$ facto de o sistema atual integrar e permitir a criação de escolas progressivas constitui em si mesmo uma promessa, como mencionado por uma das entrevistadas: “Bem, 
é notável que desde os anos setenta tenhamos um número de escolas públicas nos EUA que usam dinheiro público para aplicar este tipo, ou que aspiram a praticar, este tipo de educação!" (E6).

\section{Lidando com a questão dos testes}

Relativamente à questão dos testes estandardizados, foram identificadas três reações principais entre as entrevistadas. Algumas insistiram na importância de manter as boas práticas no sentido de assegurar bons resultados nos testes. Outras realçaram a importância de usar métodos e estratégias criativos e de incluir novas tecnologias, a fim de lidar com a questão dos testes e não cair num mero "ensinar para o teste". Como salientado por uma das educadoras:

O que eu penso que está a acontecer é que uma série de indivíduos pensa de si para si, toca a andar, toca a colocar umas palas, está a ver, toca a maquiar a coisa, mas depois nós não vamos ensinar dessa forma, vamos fazer os testes porque tem de ser, não queremos, mas tem de ser, mas vamos ensinar de forma diferente para preparar para os testes. (E3)

Enfrentar este sistema de prestação de contas exige, no entender de várias das entrevistadas, a reunião de evidências (dados qualitativos e quantitativos) que permitam divulgar o trabalho bem feito pelas escolas progressivas.

\section{Discussão}

Os resultados deste estudo indicam que as educadoras identificam como base e característica principal da educação progressiva o facto de ser uma educação orientada para o aluno. Isto implica, antes de mais, a concepção de uma educação personalizada, que seja capaz de ter em conta a especificidade da criança/estudante e, simultaneamente, de acolher a heterogeneidade e pontos de vista diferentes, de modo a favorecer a prossecução de objetivos comuns. Desse modo, sendo uma abordagem educativa centrada na criança, a educação progressiva é, igualmente, uma abordagem centrada na comunidade, um entendimento que enraíza no pensamento de Dewey e que foi recentemente enfatizado por Meier (2002b).

A concepção deste tipo de aprendizagem requer, no entendimento das educadoras entrevistadas, um ambiente estruturado que proporcione orientação e que seja, simultaneamente, aberto à participação dos adultos, professores e comunidade envolvente. A ênfase dada à estruturação da aprendizagem, que implica uma planificação cuidadosa por parte dos professores, nega a opinião muito difundida - identificada por Norris (2004) e por Shaker e Heilman (2008) como um mal-entendido -, 
segundo a qual a educação progressiva promove a falta de firmeza, não permitindo o exercício da autoridade adulta requerido pelas crianças de hoje (ZIMILES, 2008). As educadoras entrevistadas contrapõem a isto que a autoridade não pode ser confundida com punição e que o objetivo da educação progressiva constitui precisamente o desenvolver a responsabilidade do aluno num contexto de responsabilidades partilhadas (MEIER, 2002a, 2002b). O papel do professor é, por conseguinte, um papel marcado pela exigência, requerendo uma reflexão e colaboração permanentes.

Como resultado mais significativo do profundo envolvimento dos estudantes na sua própria educação, as entrevistadas assinalam a capacidade de desenvolver e adquirir uma voz própria no seio do grupo, tendo em conta perspectivas diversas e sendo capaz de conviver com as mesmas. A base disto reside numa educação baseada na experiência que fortalece "a disposição para partilhar e a coragem de mudar" (ROSKELLY, 2009, p. 207, tradução nossa), características que podem ser identificadas como fundamentais para promover uma vida democrática, entendida no sentido forte de uma vida comunitária (DEWEY,1997a).

O desenvolvimento do pensamento crítico e da capacidade de se expressar, com base em experiências estimulantes, é considerado como crucial para a obtenção de uma cidadania plena e para o assegurar de uma igualdade efetiva entre todas as crianças. Contrariamente a este desígnio, as políticas educacionais nos EUA têm vindo a criar e a aprofundar as desigualdades sociais. Esta crítica vai ao encontro da formulada por Purpel (2009), segundo o qual as medidas implementadas consistem num tortuoso processo de seleção dos vencedores e perdedores do amanhã.

\section{Conclusão}

Os resultados deste estudo permitem-nos aceder a algumas das percepções dos educadores novaiorquinos que trabalham em contextos progressivos. As opiniões expressas realçam a fundamentação da educação progressiva na especificidade da aprendizagem humana. Este é um processo marcado pela inteligência e a criatividade do aprendente. Nesse sentido, não pode ser assimilada a uma mera imitação, envolvendo uma reconstrução da experiência, na interseção da experiência própria com a dos demais, e com o objetivo de alargá-la.

A ideia de uma educação reconstrutiva e transformativa, que pode ser identificada como o núcleo do pensamento de Dewey, abre o caminho a uma verdadeira concepção democrática de educação. Contra a atual insistência na eficiência do sistema, que marca o cenário educacional nos EUA, os educadores progressivos acentuam a importância de promover a capacidade de intervir no mundo real, 
ambicionando dotar os estudantes da capacidade de pensar criticamente e de assumir compromissos relacionados com questões de justiça social e de sustentabilidade.

\section{Notas}

1. Revisão Descritiva da Criança. Metodologia inspirada nos ideais progressivos, nomeadamente na defesa de uma abordagem pedagógica centrada na criança e desenvolvida por Patricia Carini em colaboração com uma rede de educadores progressivos. A revisão descritiva da criança tem como objetivo descrever as capacidades e potencialidades de cada criança, baseando-se numa observação naturalista da mesma na sala de aula e na escola. Enraizada numa perspectiva fenomenológica, procura compreender uma determinada criança em particular, assumindo um pendor narrativo e fugindo a qualquer tipo de generalizações ou categorizações. Pressupõe um trabalho colaborativo, que resulta de uma reflexão em grupo por um conjunto de educadores e que segue determinados passos.

2. No Child Left Behind (NCLB). Legislação aprovada pelo Congresso sob a administração Bush em 2001 e promulgada pelo presidente Bush em 2002, com o objetivo de melhorar progressivamente o sucesso das escolas básicas e secundárias norte-americanas e eliminar as disparidades ao nível das competências dos alunos nas áreas da Leitura e Matemática, tendo como meta conseguir que sejam todos proficientes nestas matérias no ano de 2014. Assenta nos seguintes princípios e estratégias: crescente prestação de contas por parte dos vários Estados, distritos escolares e escolas; maior margem de escolha das escolas por parte dos pais e estudantes; maior flexibilidade dos Estados e agências educacionais locais no uso da verba federal atribuída à educação; grande ênfase dada à capacidade de leitura, especialmente em crianças pequenas. Neste contexto, cada Estado deverá desenvolver um sistema de prestação de contas aplicável a todas as escolas e estudantes, definindo, a partir de 2005/2006, critérios para a avaliação da Leitura e Matemática ao longo de escolaridade e implementando um sistema de testes anuais para todos os alunos (entre o $3^{\circ}$ e o $8^{\circ}$ grau) naquelas escolas, assim como a pontuação a ser obtida por cada grupo de estudantes. A partir de 2007/2008, os alunos deverão ser testados em Ciências, pelo menos uma vez, ao longo do ensino elementar, médio e secundário (UNITED STATES, 2002).

3. Testes estandardizados. Os testes anuais, aplicados por cada Estado no âmbito das disposições do No Child Left Behind, consistem em testes estandardizados, isto é, testes construídos com base numa metodologia de avaliação que garanta que os vários itens constantes da prova sejam fiáveis e válidos e que sejam administrados a todos os estudantes nas mesmas condições. As questões que compõem o teste são de resposta sim/não e de escolha múltipla. A pontuação obtida tem efeitos vários, condicionando nomeadamente a progressão dos alunos, a possibilidade de obterem o diploma do ensino secundário, a manutenção do emprego por parte dos docentes e o fecho de escolas públicas ou a sua privatização (UNITED STATES, 2002).

\section{Referências}

ARONSON, J. A pragmatic view of thematic analysis. The Qualitative Report, v. 2, n.1, 1994. Disponível em: <http://www.nova.edu/ssss/QR/BackIssues/QR2-1/aronson. html>. Acesso em: 1 jun. 2010.

CARINI, P. Introduction: a page from the prospect album. In HIMLEY, H.; CARINI, P. (Org.). From another angle: the prospect center descriptive review of the child. New York: Teachers College, 2000, p. 1-7. 
DEWEY, J. The child and the curriculum. Chicago: University of Chicago, 1902.

DEWEY, J. Democracy and education. New York: Simon \& Schuster, 1997a.

DEWEY, J. Experience and education. New York: Simon \& Schuster, 1997b.

FEREDAY, J.; MUIR-COCHRANE, E. Demonstrating rigor using thematic analysis: a hybrid approach of inductive and deductive coding and theme development. International Journal of Qualitative Methods, Alberta, v. 5, n. 1, p. 1-11, 2006. Disponível em: $<$ http://www.ualberta.ca/ iiqm/backissues/5_1/pdf/fereday.pdf $>$. Acesso em: 10 maio 2010.

GODMAN, J. Reforming schools: working within a progressive tradition during conservative times. New York: State University of New York, 2006.

GUBA, E.; LINCOLN, Y. Do inquiry paradigm imply inquiry methodologies? In: FETTERMAN, D.M. (Org.). Qualitative approaches to evaluation in education: the silent scientific revolution. London: Praeger, 1988.

KOHN, A. NCLB and the effort to privatize public education. In: MEIER, D.; WOOD, G. (Org.). Many children left behind: how the No Child Left Behind is damaging our children and our schools. Boston: Beacon, 2004. p. 79-97.

KRECHEVSKY, M.; RIVARD, M.; BURTON, F.R. Accountability in three realms: making learning visible inside and outside the classroom. Theory into Practice, Columbus, n. 49, p. 64-71, 2010.

MEIER, D. In schools we trust. Boston: Beacon, 2002a.

MEIER, D. The power of their ideas: lessons for America from a small school in Harlem. Boston: Beacon, 2002b.

NEILL, M. Leaving no child behind: overhauling NCLB. In: MEIER, D.; WOOD, G. (Org.). Many children left behind: how the No Child Left Behind is damaging our children and our schools. Boston: Beacon, 2004. p. 101-119.

NODDINGS, N. What does it mean to educate the whole child? Educational Leadership, Washington, DC, v. 63, n. 1, p. 8-13, set. 2005.

NORRIS, N. The promise and failure of progressive education. Lanham, MD: Scarecrow Education, 2004.

PURPEL, D. Educating and schooling in the 21st century: the role of the profession. In: SHAPHIRO, H.S. (Org.). Education and hope in troubled times: visions of change for our children's world. New York: Routledge, 2009. p. 14-28.

RAVITCH, D. Death and life of the great American school system. New York: Basic Books, 2010. 
ROSKELLY, H. Teaching like wessels. In: SHAPHIRO, H.S. (Org.). Education and hope in troubled times: visions of change for our children's world. New York: Routledge, 2009. p. 198-209.

SEMEL, S.F. Progressive education. In: PROVENZO JUNIOR, E.; PROVENZO, A.B. (Ed.). Encyclopedia of the social and cultural foundations of education. London: Sage, 2008. Disponível em: <http://www.sage-ereference.com/foundations/Article_n297.html>. Acesso em: 13 Abr. 2010.

SHAKER, P.; HEILMAN, E. Reclaiming education for democracy: thinking beyond No child left behind. New York: Taylor \& Francis, 2008.

SHAPHIRO, H.S. Introduction: education and hope in troubled times. In: SHAPHIRO, H.S. (Org.). Education and hope in troubled times: visions of change for our children's world. New York: Routledge, 2009. p. 1-13.

UNITED STATES. Public Law n. 107-110, 107th Congress, jan. 8, 2002. No Child Left Behind Act of 2001. Washington, DC, 2002.

ZIMILES, H. A bittersweet appraisal of progressive education. Society, v. 45, n. 2, p. 164-169, 2008.

Recebido em 1 de novembro de 2011.

Aprovado em 14 de fevereiro de 2014. 